\title{
O labor do Tribunal de Xustiza da Unión Europea na protección dos consumidores no ámbito bancario á luz da sentenza (Sala Cuarta) de 16 de xullo de 2020
}

https://doi.org/10.21814/uminho.ed.30.24

\author{
Marta Otero Crespo \\ Profesora contratada doutora de Dereito civil \\ Universidade de Santiago de Compostela
}

\section{Introdución}

O propósito desta contribución é bosquexar unha aproximación ao rol que está a desenvolver o Tribunal de Xustiza da Unión Europea (TXUE) no ámbito de protección dos consumidores europeos na súa tarefa interpretativa da Directiva 93/13/CEE do Consello, de 5 de abril, sobre as cláusulas abusivas nos contratos celebrados con consumidores. Para elo, tomaremos como punto de partida casos con orixe na xurisdición española.

A xustificación deste traballo ven dada porque ao longo dos últimos anos, no período comprendido entre 2010 e 2020, de acordo coa información dispoñible na páxina web do Consejo General del Poder Judicial e atendendo ao criterio sede por materia "Protección de consumidores", os tribunais españois teñen formulado 96 cuestións prexudiciais perante o TXUE, cifra que da boa conta do importante labor que está a realizar neste campo e que, pola súa propia competencia, transcende máis aló da xurisdición española ${ }^{1}$.

Así, entre os casos máis recentes e salientables podemos remitirnos á xurisprudencia recaída no eido de protección dos clientes bancarios por mor da contratación con condicións xerais nas que se insiren cláusulas abusivas. Neste senso cómpre destacar as sentenzas do TXUE que afectan aos contratos de préstamo hipotecario celebrados con consumidores de 21 de decembro de 2016 (sobre as cláusulas chan), de 26 de marzo de 2019 (relativa ás cláusulas de vencemento anticipado²),

1 Aspectos internacionales. Cuestiones prejudiciales iniciadas ante el Tribunal de Justicia de la Unión Europea, Datos, Cuestiones Prejudiciales 1998-2020, criterio "Protección de consumidores", [consultado en 2021-05-09]. Dispoñible na World Wide Web: <https://www.poderjudicial.es/cgpj/es/Temas/Estadistica-Judicial/Estadistica-por-temas/Aspectos-internacionales/Cuestiones-prejudiciales-iniciadas-ante-el-Tribunal-de-Justicia-de-la-Union-Europea/>.

2 CARBALLO FIDALDO, Marta - Intereses de demora y vencimiento anticipado del crédito hipotecario en el marco de la legislación sobre cláusulas abusivas y en la ley de contratos de crédito inmobiliario. "Boletín del Ministerio de Justicia”, Año LXXIII - Octubre 2020, pp. 26 e ss. 
de 3 de marzo de 2020 (sobre o índice IRPH ${ }^{3}$ ) ou o pronunciamento de 16 de xullo de 2020 (en materia de cláusulas relativas aos gastos derivados da contratación de préstamos hipotecarios, prescrición de accións e imposición de custas procesuais) ${ }^{4}$.

A abordaxe dos principais puntos de todas as resolucións exemplificativas citadas, xunto co estudo do seu impacto no Dereito positivo e nas decisións dos tribunais nacionais españois excedería das limitacións formais impostas, de aí que, pola súa proximidade no tempo, nos deteñamos no derradeiro dos pronunciamentos citados: a sentenza do Tribunal de Xustiza (Sala Cuarta) de 16 de xullo de 2020 (ECLI:EU:C:2020:578).

\section{A sentenza do Tribunal de Xustiza da Unión Europea (Sala Cuarta) de 16 de xullo de 2020}

A sentenza do Tribunal de Xustiza da Unión Europea (Sala Cuarta) de 16 de xullo de 2020 ven a coñecer de quince cuestións prexudiciais que teñen por obxecto a interpretación dos artigos 3 a 8 da citada Directiva 93/13. As peticións enmárcanse no contexto de dous litixios, os asuntos acumulados C-224/19 e C-259/19, procedentes do Xulgado de Primeira Instancia núm. 17 de Palma de Mallorca e do Xulgado de Primeira Instancia e Instrución núm. 6 de Ceuta, respectivamente ${ }^{5}$, referidos a préstamos hipotecarios concluídos con consumidores.

Tendo en conta o volume e a heteroxeneidade das preguntas formuladas, o TXUE as agrupa sistematicamente en cinco bloques: o primeiro, relativo á cláusula correspondente aos gastos de constitución e cancelación da hipoteca; o segundo, referido á cláusula que impón unha comisión de apertura; o terceiro, que aborda o eventual desequilibrio significativo dos dereitos e obrigacións das partes derivado desta cláusula; o cuarto, sobre a limitación no tempo dos efectos da declaración de nulidade dunha cláusula abusiva; e, finalmente, o quinto, relativo ao sistema nacional de distribución de custas procesuais no marco dos procesos que versan sobre a nulidade das cláusulas abusivas.

Nós, aos efectos expositivos, ofreceremos unha sistematización practicamente idéntica, como pasamos a expor.

3 CASTILLO MARTÍNEZ, Carolina del Carmen - Consideraciones sobre la cláusula IRPH a la luz de sus antecedentes y de la doctrina consolidada del Tribunal de Justicia de la Unión Europea. "Rev. Boliv. de Derecho", $N^{\circ}$ 31, enero 2021, pp. 504- 549.

4 TAPIA HERMIDA, Alberto J. - Nueva jurisprudencia bancaria del TJUE. “Diario La Ley”, Nº 9691, Sección Tribunal, 8 de septiembre de 2020, Wolters Kluwer.

5 Auto 47/2019, de 12 de marzo (ECLI:ESJJPI:2019:1A) e auto de 13 de marzo (ECLI:ES.JPII:2019:2A). 


\subsection{As cláusulas relativas aos gastos de constitución e de cancelación derivados da formalización do préstamo hipotecario}

O TXUE, a propósito das cuestións prexudiciais primeira a sexta no asunto C-224/19 e das dúas cuestións prexudiciais no asunto C-259/19, relativas aos efectos da nulidade da cláusula que estipula os gastos de constitución e cancelación da hipoteca, lembra que segundo a súa propia xurisprudencia, declarada a abusividade dunha cláusula e, en consecuencia, a súa nulidade, o xuíz nacional debe, de conformidade co disposto no artigo 6 da Directiva 93/13, deixar sen aplicación tal cláusula coa fin de que non produza efectos vinculantes para o consumidor, salvo que este se opoña. Neste senso, un xuíz nacional non ten atribuída a facultade de modificar o contido dunha cláusula abusiva - posto que podería contribuír a eliminar o efecto disuasorio pretendido no caso do seu emprego por profesionais. Polo tanto, cabe alcanzar a conclusión de que en principio, unha cláusula contractual declarada abusiva nunca ten existido, de xeito tal que non poderá ter efectos fronte ao consumidor, procedendo o restablecemento da situación de feito e de Dereito na que se atopaba o consumidor de non ter existido dita cláusula. 0 anterior, xustificaría a aplicación ao caso daquelas disposicións de Dereito nacional que poidan regular o reparto dos gastos relativos á constitución e a cancelación da hipoteca en defecto de acordo entre as partes implicadas. Seguindo cos argumentos do TXUE, se estas disposicións fan recaer sobre o prestatario a totalidade ou unha parte destes gastos, o consumidor pode verse obrigado a soportar estes custos.

En definitiva, segundo o TXUE, "o artigo 6, apartado 1, e o artigo 7, apartado 1, da Directiva 93/13 deben interpretarse no sentido de que se opoñen a que, en caso de nulidade dunha cláusula contractual abusiva que impón ao consumidor o pago da totalidade dos gastos de constitución e cancelación de hipoteca, o xuíz nacional negue ao consumidor a devolución das cantidades abonadas en virtude desta cláusula, salvo que as disposicións de Dereito nacional aplicables en defecto de tal cláusula impoñan ao consumidor o pago da totalidade ou dunha parte deses gastos".

\subsection{As cláusulas relativas á imposición do aboamento dunha comisión de apertura}

En segundo lugar, o TXUE examina as cuestións prexudiciais sétima a décima no asunto C-224/19, relativas ao control do carácter abusivo e da transparencia da cláusula que impón o pago dunha comisión de apertura. Pois ben, neste caso o órgano remitente cuestiona se o artigo 3, o artigo 4, apartado 2, e o artigo 5 da Directiva 93/13 deben interpretarse no sentido de que se opoñen a unha xurisprudencia nacional que exclúe a apreciación do carácter abusivo dunha cláusula contractual que impón ao consumidor o pago dunha comisión de apertura por ser tal comisión un elemento do prezo do contrato ex artigo 4.2 da Directiva 93/13, e que, ao mesmo tempo, considera que tal cláusula cumpre por si mesma a esixencia de transparencia que impón esta última disposición. 
No caso, polos razoamentos contidos nos apartados 56 e seguintes - aos que nos remitimos-, o TXUE delimita o que ha de entenderse por obxecto principal do contrato e por prestacións accesorias. Así, constitúen o obxecto principal do contrato as cláusulas que regulan as prestacións esenciais, que o caracterizan; namentres, son accesorias aquelas que non definan a esencia mesma da relación contractual. En consecuencia, ha de ser o órgano nacional o que valore se a cláusula é ou non un compoñente esencial do contrato de préstamo hipotecario, atendendo a natureza, ao sistema xeral, as estipulacións do propio contrato, así como ao contexto xurídico e fáctico. Descartado que os conceptos de "obxecto principal do contrato" e de "prezo" no sentido do artigo 4.2 Directiva 93/13, sexan coincidentes co de "custo total do crédito para o consumidor" do artigo 3, letra g) da Directiva 2008/48/CE, remata proclamando que "unha comisión de apertura non pode considerarse unha prestación esencial dun préstamo hipotecario polo mero feito de que tal comisión estea incluída no custo total deste".

En definitiva, considera que "(...) O feito de que unha comisión de apertura estea incluída no custo total dun préstamo hipotecario non implica que sexa unha prestación esencial deste. En calquera caso, un órgano xurisdicional dun Estado membro está obrigado a controlar o carácter claro e comprensible dunha cláusula contractual referida ao obxecto principal do contrato, con independencia de se o artigo 4, apartado 2, desta Directiva foi trasposto ao ordenamento xurídico dese Estado membro".

E sobre esta mesma comisión, por referencia á undécima cuestión prexudicial no asunto C-224/19, a propósito do presunto desequilibrio importante que causaría a imposición do seu aboamento ao consumidor, o TXUE considera que de conformidade co artigo 3.1 da Directiva 93/13, unha cláusula como a enunciada, na que se impón o pago dunha comisión de apertura, en detrimento do consumidor, contrariamente ás esixencias da boa fe, causa un "desequilibrio importante entre os dereitos e obrigas das partes que se deriven do contrato, cando a entidade financeira non demostre que esta comisión responde a servizos efectivamente prestados e gastos nos que incorrese, extremo cuxa comprobación incumbe ao órgano xurisdicional remitente".

\subsection{Sobre a limitación dos efectos derivados da declaración de nulidade e o establecemento dun prazo de prescrición}

Na décimo terceira cuestión prexudicial do asunto C-224/19, o órgano xurisdicional pregunta se 0 artigo 6, apartado 1, e o artigo 7, apartado 1, da Directiva 93/13 deben interpretarse no sentido de que non se opoñen a unha xurisprudencia nacional que prevé que o exercicio da acción dirixida a facer valer os efectos restitutorios da declaración da nulidade dunha cláusula contractual abusiva quede sometido a un prazo de prescrición, aínda que, en virtude da lexislación nacional, a acción para declarar a nulidade absoluta dunha cláusula contractual abusiva sexa imprescritible.

O certo é que, pese a complexidade da cuestión, atendendo a delimitación realizada no texto do auto de remisión da cuestión, o TXUE recorda que a protección dispensada 
aos consumidores pola Directiva 93/13 non é absoluta, polo que o Dereito da Unión non se opón a unha normativa nacional que, á vez que recoñece o carácter imprescritible da acción de nulidade, suxeita a un prazo de prescrición a acción dirixida a facer valor os efectos restitutorios desa declaración, sempre e cando se respecten "os principios de equivalencia e efectividade".

En definitiva, de novo, "o artigo 6, apartado 1, e o artigo 7, apartado 1, da Directiva 93/13 deben interpretarse no sentido de que non se opoñen a que o exercicio da acción dirixida a facer valer os efectos restitutorios da declaración da nulidade dunha cláusula contractual abusiva quede sometido a un prazo de prescrición, sempre que nin o momento en que ese prazo comeza a correr nin a súa duración fagan imposible na práctica ou excesivamente difícil o exercicio do dereito do consumidor para solicitar tal restitución".

\subsection{Sobre o sistema de distribución de custas procesuais}

Mediante a súa duodécima cuestión prexudicial no asunto C-224/19, formúlase se o artigo 6, apartado 1, e o artigo 7, apartado 1, da Directiva 93/13 deben interpretarse no sentido de que se opoñen a un réxime que permite que o consumidor cargue cunha parte das custas procesuais en función do importe das cantidades indebidamente abonadas que lle son restituídas por mor da declaración da nulidade dunha cláusula abusiva. De feito, de acordo co artigo 394 da Lei de Axuizamento Civil (LAC), estimada integramente a acción de nulidade dunha cláusula contractual abusiva, pero so parcialmente a acción restitutoria, o consumidor podería cargar cunha parte das custas procesuais en función do importe das cantidades indebidamente abonadas.

Polo exposto, tanto "o artigo 6, apartado 1, o artigo 7, apartado 1 da Directiva 93/13, así como o principio de efectividade, deben interpretarse no sentido de que se opoñen a un réxime que permite que o consumidor cargue cunha parte das custas procesuais en función do importe das cantidades indebidamente pagas que lle son restituídas por mor da declaración da nulidade dunha cláusula contractual por ter carácter abusivo, dado que tal réxime crea un obstáculo significativo que pode disuadir aos consumidores de exercer o dereito, conferido pola Directiva 93/13, a un control xudicial efectivo do carácter potencialmente abusivo de cláusulas contractuais".

\section{0 impacto da STXUE de 16 de xullo de 2020 no ordenamento xurídico español}

\subsection{Aspectos coincidentes}

Poucos días despois do ditado da sentenza do TXUE, a Sala Primeira do Tribunal Supremo, na súa sentenza de 24 de xullo de 2020 (ECLI:ES:TS:2020:2495), determinaba que a súa xurisprudencia anterior resultaba plenamente compatible co ditaminado polo TXUE. En concreto, no seu Fundamento Xurídico Terceiro, o Alto Tribunal español compara diferentes aspectos contidos na sentenza do TXUE, referidos a nulidade de cláusulas de gastos, coa xurisprudencia da Sala, proclamando de novo que 
declarada nula unha cláusula contractual nun préstamo hipotecario por imputación indiscriminada dos gastos ao consumidor, habería que aplicar as consecuencias derivadas de tal nulidade. No asunto, o Tribunal Supremo impón o abono pola entidade financeira dos gastos rexistrais e a metade dos notariais, mentres que será o consumidor quen teña que soportar o pago do Imposto de Actos Xurídicos Documentados.

\subsection{Aspectos diverxentes ou escuros}

Na sentenza anterior non se abordan outras cuestións, como, por exemplo, a posible abusividade da comisión de apertura. Con todo, non podemos esquecer que o 23 de xaneiro de 2019 (ECLI:ES:TS:2019:102), o Tribunal Supremo establecera que a comisión de apertura formaba parte do prezo, polo que non podería ser declarada abusiva se superaba o control de transparencia. O Alto Tribunal tras analizar a normativa ad hoc, sostivo que esta última estaba destinada a garantir a súa transparencia, estando xustificada a comisión na medida na que supuña un cobro por actuacións "inherentes á actividade da empresa ocasionada pola concesión do préstamo ou crédito”. Formaría así parte do prezo, e o principio de realidade do servizo remunerado, non esixiría nada distinto da concesión do propio préstamo. En suma, o Tribunal Supremo consideraba que a comisión de apertura formaba parte do prezo, a diferencia do TXUE, estando plenamente xustificada o seu cobro polo propio feito da concesión do préstamo, polo que podemos agardar un posible xiro xurisprudencial neste senso ${ }^{6}$.

Outro punto escuro, sitúase no tocante a prescrición das accións para solicitar a devolución dos gastos indebidamente abonados en virtude da aplicación dunha cláusula abusiva. Malia que a acción para a declaración de abusividade dunha cláusula sexa imprescritible, non sucede o mesmo con respecto á restitución dos pagos realizados en virtude da aplicación de tal cláusula ${ }^{7}$. Neste punto, o TXUE deixa aberta a porta a aplicación de calquera prazo de prescrición nos termos apuntados. Na práctica, o quid da cuestión está a residir na determinación do dies a quo para o cómputo do actual prazo de 5 anos previsto no artigo 1964 CC, propoñéndose como opcións, entre outras, a data do 23 de xaneiro de 2019 (por pronunciarse nesta data o Tribunal Supremo sobre a nulidade de determinadas cláusulas relativas a gastos hipotecarios).

Finalmente, polo que se refire as custas procesuais, a visión pro consumatore do TXUE xa viña sendo aplicada polo Tribunal Supremo, se ben en supostos con matices

6 Parte da doutrina considera que non existen motivos para modificar o posicionamento do Tribunal Supremo. Así, PANTALEÓN, Fernando - La comisión de apertura, el Tribunal de Justicia y el Tribunal Supremo (I), “Almacén de Derecho", [consultado en 2021-05-09]. Dispoñible na World Wide Web: <https://almacendederecho.org/la-comision-de-apertura-el-tribunal-de-justicia-y-el-tribunal-supremo-i>.

7 Non se trata dunha cuestión unánime, posto que existen posicionamentos doutrinais e xurisprudencia menor que defenden que só procede exercer a acción de restitución unha vez declarada a nulidade da cláusula, posto que ata ese momento os titulares non poden coñecer as consecuencias derivadas de tal declaración; neste senso, a restitución das cantidades derivadas da indebida aplicación da cláusula de gastos tampouco prescribiría. Sobre estes aspectos, AYO JIMÉNEZ, Gonzalo - Actualidad sobre la prescripción de la restitución de gastos hipotecarios.“El Derecho” [consultado en 2021-05-09]. Dispoñible na World Wide Web: <https://elderecho.com/actualidad-sobre-la-prescripcion-de-la-restitucion-de-gastos-hipotecarios>. 
distintos (nos que non podemos deternos), desde a súa sentenza do Pleno do 4 de xullo de 2017 (ECLI:ES:TS:2017:2501), sentando a súa interpretación dos artigos 394 e 398 LAC conforme ao principio xeral do vencemento en relación cos principios de non vinculación do consumidor ás cláusulas abusivas e de efectividade do Dereito da Unión - fallando, en definitiva, a imposición das custas á entidade demandada. A anterior, súmanse agora varias resolucións posteriores á STXUE de 16 de xullo de 2020, nas que podemos destacar a recente de 8 de marzo de $2021^{8}$, na que se recompilan os derradeiros pronunciamentos sobre imposición de custas nos supostos de declaración de abusividade de cláusulas inseridas en contratos de préstamo hipotecario. Nelas insístese na necesidade de atender ao principio de primacía do Dereito da UE, que obriga aos xuíces dos Estados membros a inaplicar unha norma de Dereito interno (relativa a custas no caso) cando a considere contraria ao Dereito da UE, por ser unha esixencia derivada dos arts. 6.1 e 7.1 da Directiva 93/13/CEE e do principio de efectividade do Dereito da UE.

Afastados do mundo académico e xurisprudencial, compre sinalar que se está a promover unha modificación do réxime de custas procesuais no Anteproxecto de Lei de medidas de eficiencia procesual do servizo público de xustiza, alterando substancialmente a actual regulación do sistema de custas procesuais ${ }^{9}$. Haberá que agardar para coñecer se finalmente cristaliza ou non ese cambio de paradigma.

8 ECLI:ES:TS:2021:864.

9 MARTÍNEZ DE SANTOS, Alberto - La regulación de las costas en el Anteproyecto de Ley de medidas de eficiencia procesal del servicio público de justicia. "Diario La Ley”, № 9839, Sección Plan de Choque de la Justicia/Tribuna, 28 de abril de 2021, Wolters Kluwer, pp. 1-10. 